\title{
THE SECURITIES PORTFOLIO MODELLING FOR EMERGING MARKETS
}

\author{
Tihomir Hunjak, Marijan Cingula \\ Faculty of Organization and Informatics Varazdin \\ Pavlinska 2, 42000 Varazdin \\ tihomir.hunjak@foi.hr,marijan.cingula@foi.hr
}

Keywords: Securities, emerging markets, portfolio building, multi-criteria decision making

Summary: The most significant differences at emerging markets, according to the other types of capital markets, include volatility, lack of regulation, and lack of liquidity. Thus, portfolio building is usually not result of standard techniques and procedures such as technical or fundamental analysis. Besides, the use of insider's information for trading at emerging markets is not always controlled and sanctioned as it is expected in other democratic countries, which have decades or even centuries of trading tradition. Corporate governance in transition countries formally follows the OECD Principles, but the implementation of ethical rules is still about starting point in many companies listed on local stock exchanges. International investors, who are crucial for economic development in countries with emerging markets, need more reliable environment for their decisions, so they should welcome establishing the multi-criteria model for building their portfolios.

\section{Introduction}

Investment decisions are usually based on technical and fundamental analysis. However, there is a need to expand quantitative and qualitative approach to build a specific investment portfolio model for emerging markets. Model used to estimate attractiveness of a single share must include different factors which could influence the final decision regarding purchase of the particular share. Some other assessment parameters must certainly be integrated into traditional mechanisms for the fundamental and technical analysis. Most often, those subjective factors are more important on emerging markets than the traditional ways of assessment. The structure of the article is as it follows: In the first part Croatian stockmarket have been described emphasizing characteristics which are important for making the right trading decision.

\section{Croatian's stock-market key characteristics}

Croatian's capital market has many characteristics, well known from emerging markets, but it also has its own specifications. Some of the typical characteristics of emerging markets primarily are slow trading, a distinctive volatility, and dependence on the local political influences (Aggarwal, Inclan, Leal, 1998).

From all the Croatian market specifications that are relevant for this task, the most significant is that there are two fully equipped stock-markets which is totally illogical for such a small country. For each one of those markets the indexes (CROBEX and VIN) have been developed. If dynamic of stock-exchanges in Croatia is observed (shown on the Picture 1), conclusions could be made which would confirm the connection between behavior on the Croatian market and events which have global meaning. Also, trends showing its development could be recognized.

At the beginning of treading on the Croatian stock-markets, trend was satisfactory until the beginning of the Asian Crises which started in Tokyo at the beginning of 1997 and it rapidly spread on all the other 
stock- markets. Its influence on the emerging markets like Russian and Croatian was faster, stronger and longer than it was on the stable stock- markets.

\section{Picture 1: Stocks trading at the Croatian stock-markets}

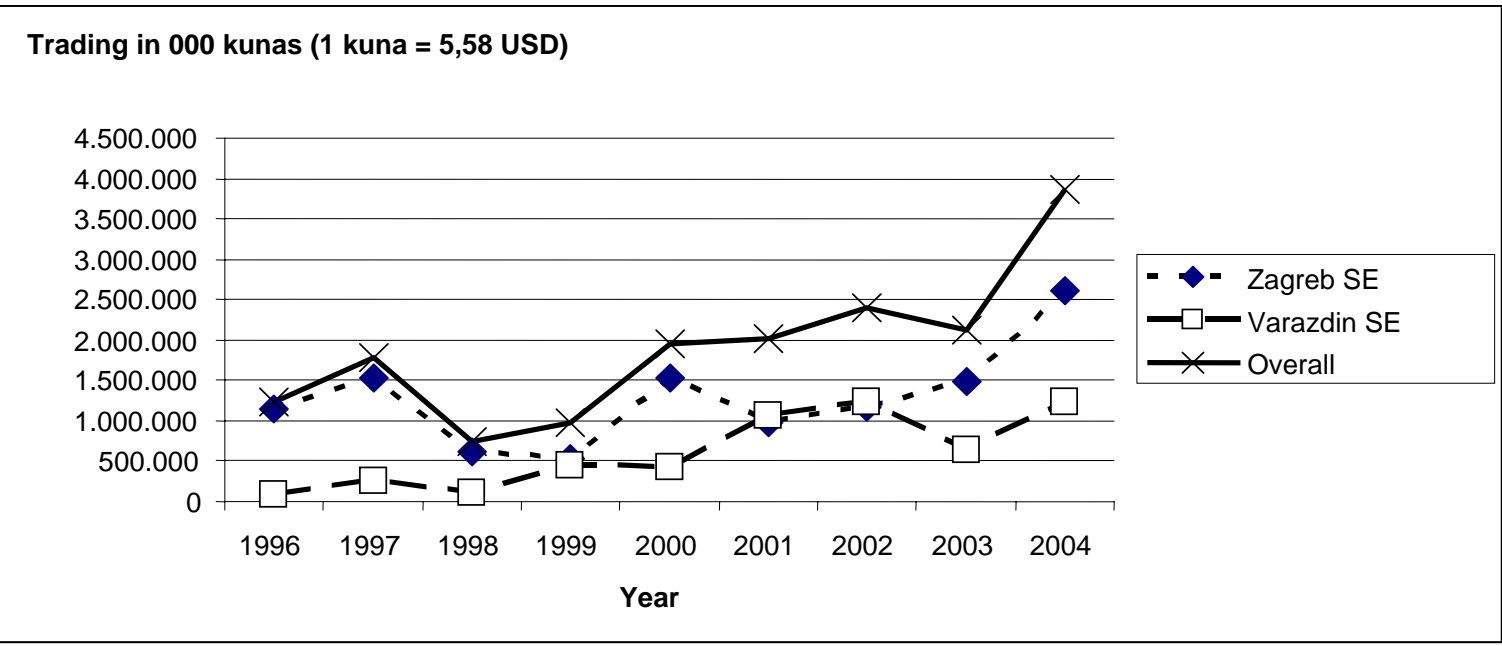

Source: Information from the Zagreb stock-market and Varaždin stock-market

The slow-down in trading on the Croatian stock-market which occurred in 1998 lasted for more than two years, so that just turnovers in 2000 exceeded trading results in 1997. After recovering from the global adverse influences, Croatian stock market was developing under the influence of the local factors, mainly under the institutional support which caused the beginning of functioning of the organized investors: privatization and pension funds. However, trading was insignificant until the middle of 2004 when Croatia's membership in the EU become certain. Trust of the foreign investors had grown so trading redoubled in a year. As two favorable facts took place: appearance of local institutional investors and entrance of foreign depositors, demand for the high-quality stocks had increased, so during the 2004 value of some stocks rose four to five time, and only in January 2005 stocks value increased for $30 \%$.

\section{Fundamental and Technical Analysis and Croatian Market}

Investors who would like to invest on the Croatian capital market cannot rely on neither technical nor fundamental analysis because trading decision cannot be based on the results of the analysis which is made in the conditions of negligible trade and high volatility. Technical analysis that relies on the market value and liquidity of a particular share (trading capitalization) is uncertain in conditions when share liquidity or its market value does not depend on its quality but on a greater or smaller presence of investors, who are often foreign.

The accuracy of this statement was proven at the moment of the capital "escape” after the Asian crisis and at the moment of the capital "return" after decision of the Croatian membership in the EU. In both cases, decrease in stocks value (average 30\% of the nominal values) or increase in their values (average 200-300\%) covered all the stocks on the market, regardless of their earlier liquidity or singular attractiveness. As the market was traditionally very superficial, certain speculations with the particular share prices were possible even for insignificant trades; therefore the importance of the technical analysis was almost completely eliminated. Fundamental analysis, which was based on the business report or on the economic attractiveness of a certain branch, also was not reliable in those circumstances. At the moment of a decrease or an increase of a whole market, a certain particular characteristic of a firm that issues stocks was insignificant for trading decision. 
The stocks value on the Croatian market primarily depended on the amount of the capital fluctuating, and only thereafter, on the business efficiency of a certain firm. Those who invested on the market are very often exposed to the subjective influences of the possible insider dealings, because on a small market is much more difficult to protect information during a critical situation for a particular firm. Besides, regulation of the whole trading system in the transitional countries is not at the same level as it in the democratic states whose requirements are very strict. Up to this point experience has shown that dominating trade motives in Croatia are in accordance with the Index ROE (Return on Equity). Also important are indexes which are compatible with the Index DOE (Debt on Equity) because the assets of the most companies are burdened with mortgages. This has occurred because dominant way of privatization was based on the Bank credits and as a mean of their insurance the companies' assets used. Because of the debts repayment liability an important criteria is a firm liquidity. Technical analysis takes into account market capitalization i.e. quantity of shares trading and their price.

On developed markets these parameters are very stable and changes are mild. Relying on the data dealing with trades and prices intensity, it is fairly reliably to conclude if a particular share is attractive to investors or not. On the volatile markets of the transitional countries, trading intensity is not constant, and prices oscillate so intensively (sometimes even on a very small quantities in trade) that the facts obtained from technical analysis have almost no value for a potential investor.

Traditionally, fundamental analysis can be a very strong analytical support in the cases when investment decision has been based on financial indexes and trading efficiency of a single stock issuer. It is especially significant to investors that their profit reaches satisfactory proportion to the capital they have invested. Also, the debt/exuity index which shows real balance values and liquidity indexes that drew attention to the ability to meet current liabilities.

In the terms of undeveloped trading on the Croatian stock-exchanges, fundamental analysis is less significant than the technical because the latter can prove that certain transactions, taking into account dynamic and prices, are completely unrelated to the business results of a stock issuer but are much more dependable on the speculation of some brokers who, with a very small quantity of stocks can cause huge price rises or falls by completely ignoring business efficiency of a company issuing the stocks. There are strong indications showing that certain brokers, who create business information and participate in technical analysis, at the same time generate transactions on the market whose main aim is to get speculative results. In the conditions of insignificant trading, they are aware that their transactions as a result have unrealistic price changes, so they have advantages comparing to other investors. Other factors which must be taken into account when trading on the Croatian stock-market are most often subjective or are dependable on external influences.

\section{Risks}

Risks factors are essential for investors' decisions; however, there are more different aspects of risks connected to the emerging markets. Croatian market, for instance, suffered from the regional political instability more than from other types of the risk.

\subsection{Market risks}

Market risk which occurs as miscalculation between supply and demand for a particular share is very real and it depends on the foreign investors' preference. As the extent of trading is modest, every single increase in the investment activity coming from abroad has significant influence on the status of a particular share. At the same time, if a certain investor acquires a sufficient controlling interest (majority half or two-third predominance), there is a possibility to completely block trading because major holder has no wish to carry out his legal duty to take-over, but is content to keep status quo. In that case, minority holders do not have any interest to buy off shares, new holders are completely uninterested, and the major holder is not interested in dividend, but only in other methods of extracting capital from the existing firm. 


\subsection{Political risk}

Political risks are usually manifested as a lack of trust in governmental politics or as an increase of instability in a region. There are strong indicators like the Corruption Index according to which Croatia is highly rated comparing to the other transitional countries. Political risks are also manifested in some Croatian specifications which include general economic boom or slump, depending on the country's current international situation, especially regarding delay in the EU membership. It is also important to consider development level of the capital market infrastructure, and especially existence and maturity of the investment and pension funds. In that context, government's attitude to trading is crucial orientation from the privatization process to the capital market i.e. sale of the big public firms past national stock-markets.

\subsection{Insider dealings}

Insider dealings are very dangerous for the transparent and objective functioning of capital market, and in the transitional countries that risk is even larger because of the non-existing (transition) and undeveloped legislative mechanisms. In small countries, information concerning business changes that could affect investor's decision are more easily available to the limited number of unauthorized people that could misuse those information when trading. Therefore, it is important to know how serious a possible buyer is and their motives (will they organize production, do they plan strategic changes in the company, do they buy property or will they continue business etc.). Perhaps the biggest possible danger for trading objectiveness is represented by the Government which could favor a buyer by canceling claims, by making guarantee for favorable credits, by giving trading contract after sale, by giving custom's privileges etc.

\subsection{AHP Model for Trading Stocks on Croatian Market}

Model which is shown on the Figure 1 is developed in order to prioritize shares which are being analyzed when trading decision are made. With slight modifications it could be customize to manage portfolio if combined with 0-1 programming. Ratings model for an assessment of a large number of stocks has not been finished up to this moment, but for most of criteria absolutely measurable scales have been defined. On the picture, the structure of criteria and their values could be seen. Values based on those assessments have not been shown, but in the previous text the context was described out of which could be concluded why this model's assessment criteria are different from the ones which could be expected for the similar model on developed market. 
Figure 1: AHP model for trading selected stocks

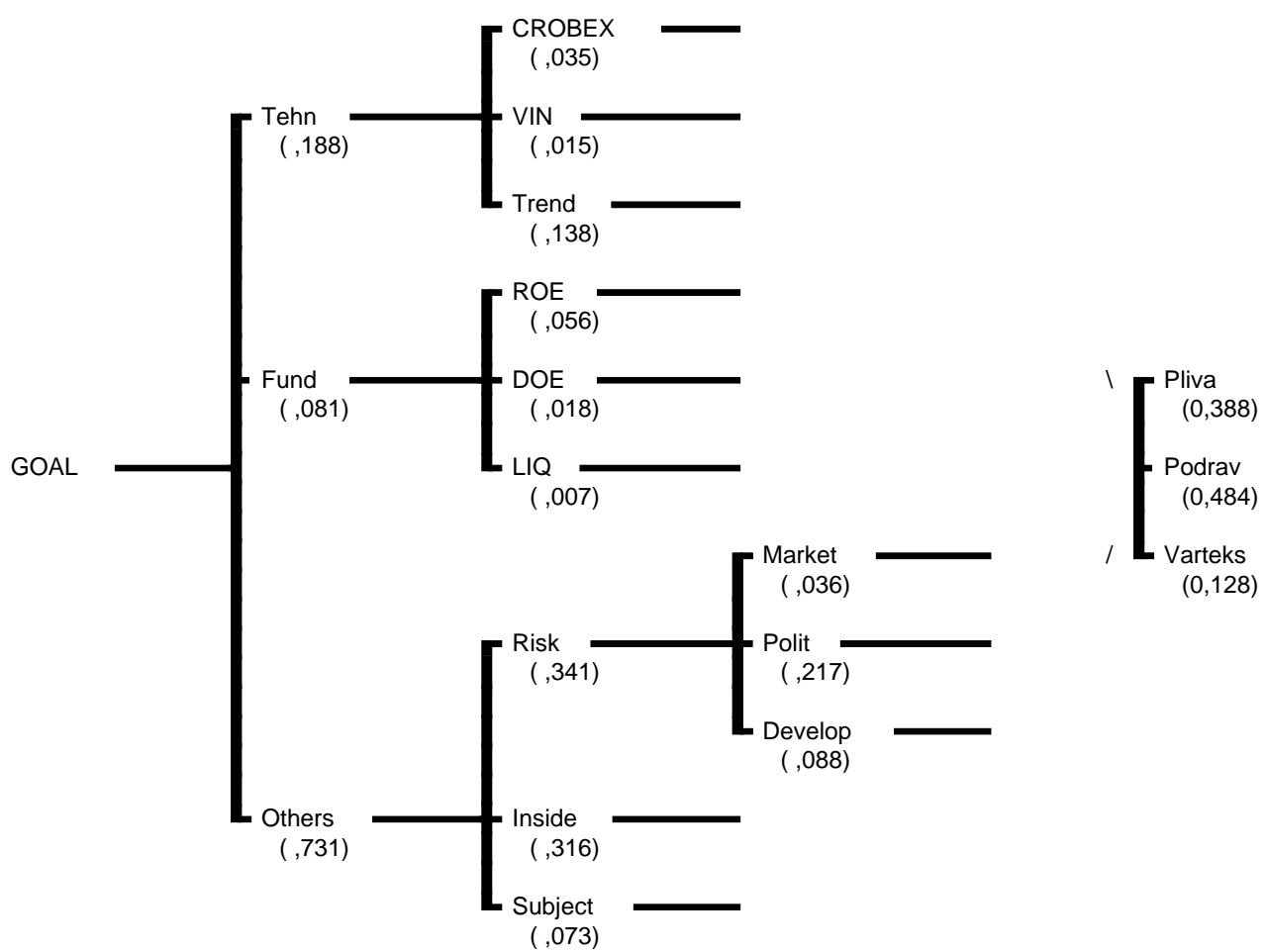

Table 1: Abbreviations list

\begin{tabular}{|l|l|}
\hline Abbreviation & Definition \\
\hline CROBEX & CROBEX index \\
\hline DOE & Debt on equity \\
\hline Develop & Risk driven by market development process \\
\hline Fund & Fundamental analysis \\
\hline Inside & Insider trading \\
\hline LIQ & Liquidity \\
\hline Market & Market risk \\
\hline Others & Other criteria \\
\hline Pliva & Pliva, pharmaceutical company \\
\hline Podrav & Podravka, food factory \\
\hline Polit & Political risk \\
\hline ROE & Return on equity \\
\hline Risk & Trading risk \\
\hline Subject & Subjective estimation \\
\hline Tehn & Tehnical analysis \\
\hline Trend & Trends in trading \\
\hline
\end{tabular}




\begin{tabular}{|l|l|}
\hline VIN & VIN index \\
\hline Varteks & Varteks, textile company \\
\hline
\end{tabular}

\section{Case study}

The usability of the model shown on Fig. 1 was checked by simulating investment attractiveness in three different types of industrial stocks, well-known on the Croatian capital market. The aim was to test the practical value of the model. Hereafter, the chosen stocks will be shortly described and the data which show a high level of irregularity in the behavior will be reveal. Those data represent additional arguments for the necessity to develop specific models for the market like the one Croatian is.

From the first quotation on the Zagreb stock-market, shares from the pharmaceutical company Pliva's were used and shares from the food company Podravka, and from the first quotation on the Varaždin stock-market, shares from the textile company Varteks.

Regardless of the successfulness level of each company or on their trading intensity, all three types of stocks have similar rise or fall in their market values which depends solely on external influences of the quantity traded (entrance of the foreign investors). Therefore, subjective evaluations are so significant for the final trading decision. On all the pictures (Picture 2, Picture 3 and Picture 4), trading data are shown for the period of the last year. On the Picture 4, the changes in the quantity traded could be seen, on the Picture 3 the changes in the price dynamic could be seen and on the Picture 2 trading rate was shown

Picture 2: Annual trading PLIVA-R-A

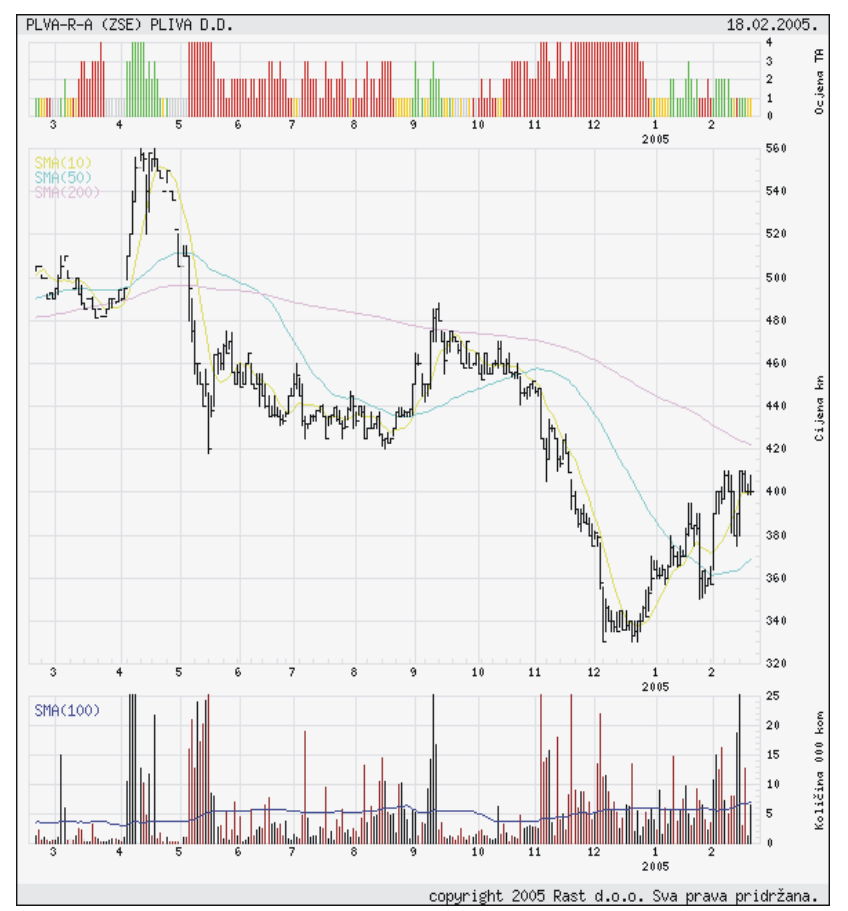

Source: http//www.rast.hr , accessed on 18th February, 2005

On the picture is shown that Pliva's stocks have been traded continuously and trading is quite high, which is understandable because stocks are on the London stock-market quotation and therefore are very interesting to the foreign investors. However, the stock price does not follow business results but only states trading intensity on the whole market. 
Picture 3: Annual trade PODR-R-A

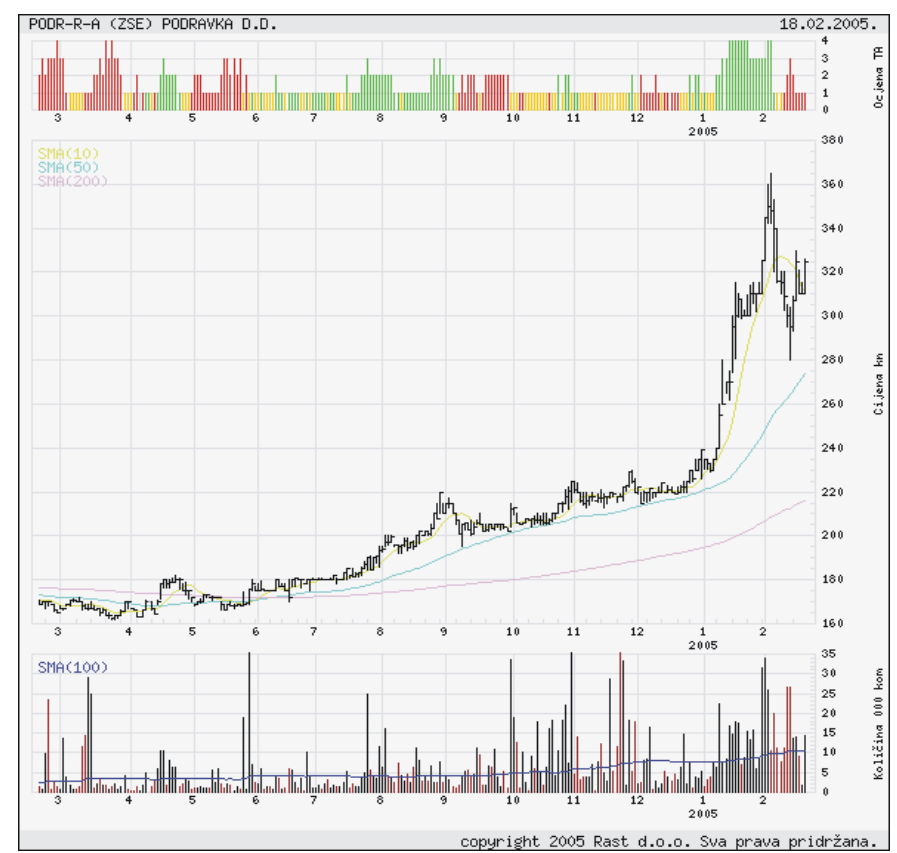

Source: http//www.rast.hr , accessed on 18th February, 2005

Food company Podravka also has a very liquid stock and high trading range, but the stock price has risen only at the end of the last year as a result of a significant number of the foreign investors' entrance at the local capital market.

Picture 4: Annual trade VART-R-A

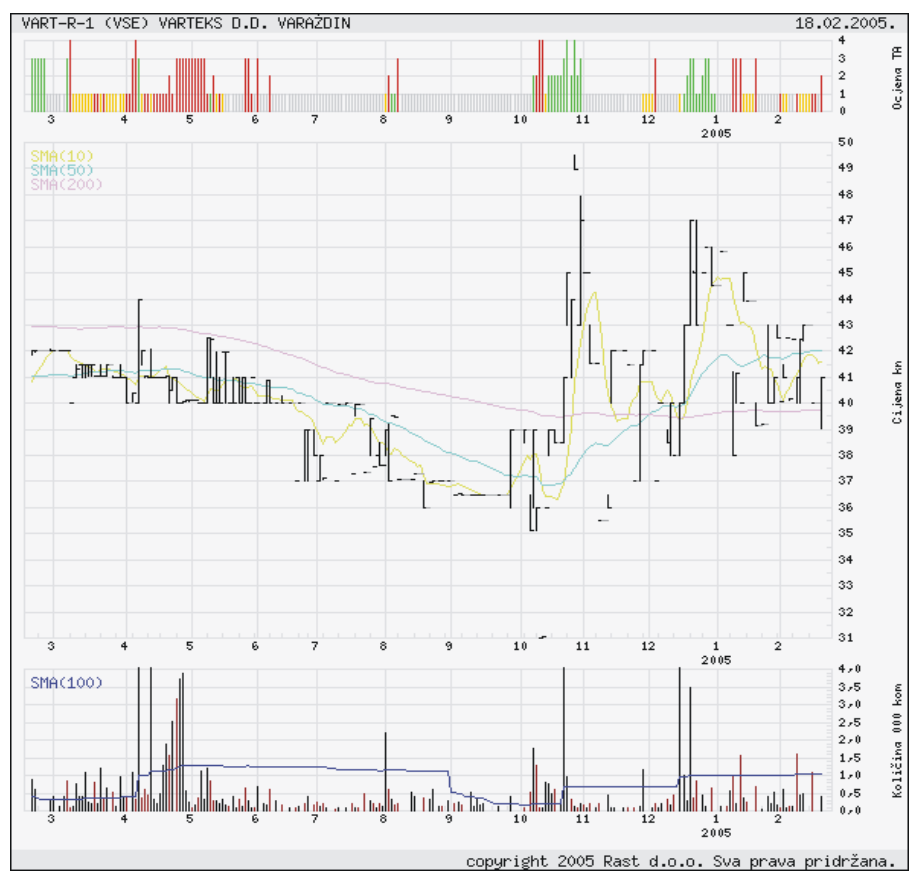


Source: http//www.rast.hr , accessed on 18th February, 2005

Textile industry is not as attractive to the investors as are pharmaceutical or food industries, and the business results are low. Extent of the stock trading is lesser because of a privatization process carried out, and stock value has increased after the Government has decided to give a credit guarantees which are used to improve results of unsuccessful dealings.

Application of the described model compared to the shares has indicated priorities as shown on Picture 5.

Picture 5: Portfolio modeling for emerging market

\begin{tabular}{ll}
\hline & $\begin{array}{c}\text { Synthesis of Leaf Nodes with respect to GOAL } \\
\text { Ideal Mode } \\
\text { OVERALL INCONSISTENCY INDEX }=0,05\end{array}$ \\
Podrav & Pliva \\
Varteks & 128
\end{tabular}

\begin{tabular}{|l|l|}
\hline Abbreviation & \multicolumn{1}{c|}{ Definition } \\
\hline Podrav & Podravka, food factory \\
\hline Pliva & Pliva, pharmaceutical company \\
\hline Varteks & Varteks, fabrics \\
\hline
\end{tabular}

As these priorities overlap the treatment given to the shares by trading participants on the Croatian stockmarkets, it could be supposed that applicability of the model described has been confirmed.

\section{Conclusion}

Emerging markets have their specifications which are result of unsettled privatization process, nonexistence of secure legislative and other reasons mentioned in the article. Because of all those reasons, the participants in the stock-market trading cannot rely on the analytical models and rules for the assessment of the stock quality which are applied on developed markets. For the specific conditions like those described in this work, it is necessary to develop models which can help create such conditions. It has been shown that the AHP method and software EXPERT CHOICE are advisable combinations for the purpose.

\section{References}

Aggarwal R., Inclan C. and Leal R. (1998), Volatility in Emerging Stock Markets, Proceeding for the Conference: Alternative Structures for Securities Markets, Capital Markets Research Center, Georgetown University, School of Business, Washington, D.C., September 10-11

http//www.rast.hr , accessed on 18th February, 2005 
Saaty, T.L. and Vargas,L.G. (1991) The Logic of Priorities, Applications in Business, Energy, Health, and Transportation, RWS Publications, Pittsburgh, PA 